\title{
Optimasi Web Profil dan Sistem Informasi Terintegrasi Sebagai Media Promosi Wisata Waduk Pondok Ngawi
}

\author{
Nanda Dwi Pamungkas ${ }^{1)}$, Ridho Pamungkas ${ }^{2)}$, Saifulloh ${ }^{3)}$ \\ Progam Studi Sistem Informasi, Universitas PGRI Madiun, \\ Jl. Setia Budi No 85, Madiun, Jawa Timur 63118 \\ E-mail: nandadwipamungkas70@gmail.com ${ }^{l}$ ridho.pamungkas@unipma.ac.id ${ }^{2)}$, saifulloh@unipma.ac.id ${ }^{3}$ )
}

\begin{abstract}
This research was conducted with the aim of designing and creating a web profile and integrated tourism information system that can present and provide tourist information in the Pondok Reservoir, Ngawi Regency. The background of this research was appointed based on the need for an information system that can provide comprehensive information quickly and accurately. There is still a lack of information that can be consumed by the wider community in relation to information on tourist attractions, especially Pondok Reservoir, so it is necessary to create an effective alternative means in informing the Pondok Reservoir tourism so that it is increasingly known by the wider community. And with this web profile and information system, it can also help the local government of the Department of Tourism and Culture in managing tourism and cultural information in the Ngawi Regency area. This study uses the waterfall system development method and the system testing method using the Black box testing method which focuses on the website function keys.
\end{abstract}

Keywords—: Information System, Tourism, Ngawi Regency, Website.

\section{PENDAHULUAN}

Sektor pariwisata merupakan salah satu kesempatan yang sangat besar untuk dikembangkan. Pariwisata adalah seluruh aspek manusia yang mendukung kegiatan wisata baik bersifat nyata maupun tidak nyata yang mempunyai tujuan untuk mewujudkan kebutuhan dan mewujudkan terciptanya kepuasan wisatawan serta berdampak positif terhadap ekonomi, kesejahteraan dan kelestarian lingkungan dan budaya di suatu kawasan wisata (Setiawan, 2016).

Sektor pariwisata menjadi salah satu sektor yang berperan penting dalam perekonomian suatu daerah utamanya dalam penambahan pendapatan daerah, yaitu memberikan kontribusi terhadap Pendapatan Asli Daerah (PAD) termasuk di Kabupaten Ngawi.

Berdasarkan berita yang dilansir oleh tulakan.ngawikab.id kontribusi sektor pariwisata terhadap PAD kabupaten Ngawi pada tahun 2020 mencapai target yang ditetapkan sebesar Rp.259 juta. Kepala Bidang Pariwisata Dinas Pariwisata Kebudayaan Pemuda dan Olahraga (Disparpora) Ngawi Totok Sugiharto menyatakan kontribusi sektor pariwisata melewati target PAD pada 2020 dengan realisasi Rp312 juta.

Kabupaten Ngawi merupakan salah satu wilayah yang memiliki potensi wisata yang besar. Kabupaten Ngawi terletak di provinsi Jawa Timur. Banyak objek wisata yang terdapat di kabupaten Ngawi yang patut

dikunjungi. Berdasarkan data Badan Pusat Statistik (BPS), Kabupaten Ngawi memiiki tempat wisata dan area wisata di Kabupaten Ngawi berjumlah 21 tempat wisata dimana Waduk Pondok menjadi salah satu destinasi wisata didalamnya.

Wisata Waduk Pondok terletak di Dusun Gandong, Desa Bringin Kecamatan Padas. Waduk Pondok sering difungsikan sebagai tempat untuk bersantai, wisata memancing, dan tempat rekreasi. Selain itu, Waduk Pondok juga difungsikan sebagai bendungan yang digunakan untuk mengairi 3 kecamatan yang berada di sekitar Waduk Pondok, yaitu Kecamatan Bringin, Padas dan Pangkur.

Saat ini, pariwisata atau tourism telah menjadi tren dan bagian dari gaya hidup modern. Wisata tidak hanya dikhususkan untuk masyarakat yang berkecukupan atau dikatakan wisatawan (Tourist) saja,tetapi juga diperuntukan bagi semua lapisan masyarakat dalam apresiasi dan budget yang berbeda. Namun Wisata Waduk Pondok sendiri masih belum 
banyak diketahui atau dikenal oleh masyarakat luas utamanya masyarakat luar Kabupaten Ngawi dikarenakan kurangnya informasi dan promosi tentang pariwisata tersebut.

Penyediaan informasi Waduk Pondok masih tergolong manual dan statis, dimana media promosinya masih sebatas melalui media pamfllet,poster dan dari mulut ke mulut dari wisatawan yang telah mengunjungi objek wisata Waduk Pondok. Selain itu dari pihak pemerintah sendiri yaitu Dinas Pariwisata Kabupaten Ngawi masih belum secara aktif memberikan informasi secara lengkap dan promosi yang maksimal terkait tempat-tempat wisata yang ada di Kabupaten Ngawi utamanya wisata Waduk Pondok sehingga membuat masyarakat luar Kabupaten Ngawi pada khususnya dan masyarakat Kabupaten Ngawi umumnya minim akan informasi.

Masih rendahnya informasi yang dapat dikonsumsi oleh masyarakat luas kaitannya dengan informasi tempat wisata, khususnya Waduk Pondok, sehingga perlu dibuatkan sarana alternatif yang efektif dalam menginformasikan wisata Waduk Pondok agar semakin dikenal oleh masyarakat luas. Salah satu sarana atau media yang dapat dijadikan sebagai upaya penyediaan informasi terkait dengan Waduk Pondok yang lengkap dan terintegrasi maka diperlukan media sistem informasi berupa web.

Optimasi web profil dan sistem informasi Waduk Pondok yang terintegrasi sangat diperlukan sebagai media informasi dan promosi kepada masyarakat luas. Oleh karena itu, Penulis hendak merancang web profil dan sistem informasi wisata Waduk Pondok berbasis web dimana para wisatawan (tourism) dapat mengetahui berbagai macam informasi tentang Waduk Pondok dan dapat melakukan transaksi seperti memesan makanan yang ada di resto Waduk Pondok.

Optimasi web profil dan sistem informasi Waduk Pondok yang terintegrasi dilakukan Penulis guna mendukung Pemerintah Kabupaten Ngawi dalam mengembangkan wisatawisata yang ada di Kabupaten Ngawi menjadi Desa Wisata. Berdasarkan keterangan yang disampaikan oleh Menteri Pariwisata dan Ekonomi Kreatif, Sandiaga Salahudidin Uno dalam kegiatan webinar "Mas Menteri Kangen Ngawi”, bahwa Ngawi memiliki banyak desa yang berpotensi menjadi desa wisata, dimana terdapat sekitar 200 desa di Ngawi yang akan dikembangkan menjadi desa wisata sebagai wujud mendorong pengembangan ekowisata di Indonesia (pwinews.id).

\section{METODE PENELITIAN}

Penelitian ini dilakukan pada Waduk Pondok yang berlokasi di Desa Gandong, Kecamatan Bringin, Kabupaten Ngawi. Dalam pengembangan system informasi ini menggunakan metode Waterfall.

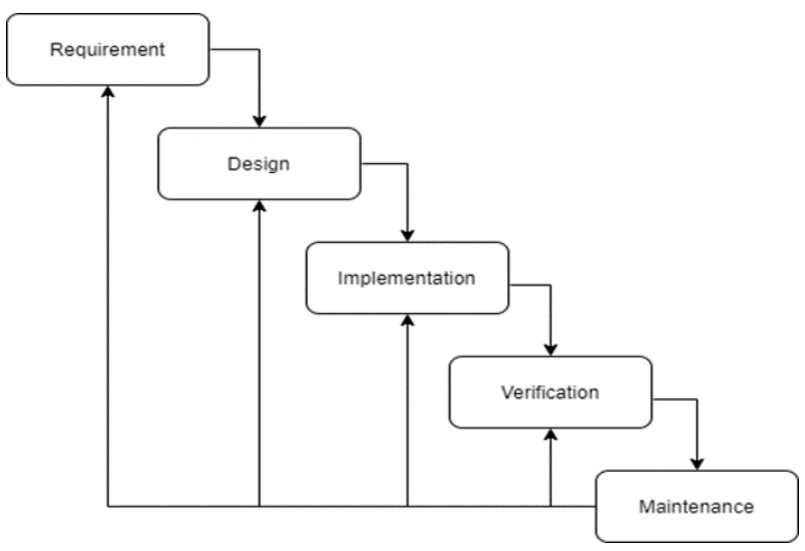

Gambar 1 Metode Waterfall 
Website : http://pilar.unmermadiun.ac.id/index.php/pilarteknologi

Tahapan metode pengembangan sistem informasi yang diterapkan yaitu metode pengembangan waterfall. Metode waterfall memiliki beberapa tahapan. Berikut beberapa tahapan prosedur pengembangan waterfall pada sistem informasi wisata :

A. Requirement ( analisis kebutuhan )

Tahapan pertama pada pengembangan ini yaitu analisis kebutuhan yang tujuannya adalah untuk memadukan data yang dibutuhkan dalam pengembangan perangkat lunak yang dibutuhkan oleh pengguna. Pengembang harus memahami informasi yang didapat dan tampilan yang dipergunakan pada tahap analisis kebutuhan terdapat beberapa tahapan meliputi wawancara, survey, dan pengamatan.

B. Desaign ( desain )

Tahap berikutnya yaitu desain, pada tahap ini akan digambarkan mengenai tampilan proses yang bisa dilakukan oleh sistem yang dikembangkan. Tampilan yang akan direncanakan mengikuti hasil dari analisis kebutuhan. Tujuan pada tahap ini adalah menggambarkan bagaimana tampilan dan bagaimana kerja dari sistem yang akan dibuat. Perancangan yang dihasilkan dari tahap desain yaitu :

1) Perancangan UML : Tahapan perancangan UML diawali dari merancang Use case Diagram, dan Activity Diagram.

2) Perancangan Interface : Perancangan interface atau tampilan antarmuka dilakukan untuk memberi gambaran desain tampilan untuk setiap halaman dari sistem informasi dan memberikan panduan pengguna sistem informasi.

C. Implementation ( pengkodean )

Tahapan implementation atau pengkodean merupakan tahapan secara nyata yang dilakukan untuk mengerjakan suatu sistem. Penulisan kode progam merupakan tahap penerjemah desain sistem yang telah dibuat dengan menggunakan bahasa pemrogaman. Pada tahap ini bahasa pemrogaman yang dipakai adalah $H T M L, C S S$, JavaScript dan PHP menggunakan aplikasi Visual Studio Code sebagai media pembaca dari bahasa pemrogaman tersebut dan pengolahan basis data menggunakan $D B M S$ versi open source yaitu $M y S Q L$.

D. Verification ( pengujian )

Tahap pengujian adalah menguji sistem untuk memastikan bahwa sIstem yang telah dibangun memenuhi persyaratan desain dan dapat beroperasi secara normal sesuai analisis dan desain tanpa kesalahan. Dalam tahapan ini peneliti menggunakan pengujian Black box testing dengan mengajukan beberapa pertanyaan mengenai fungsi sistem kepada pengguna dan memberikan 4 kategori jawaban yaitu sangat tidak setuju, tidak setuju, setuju dan sangat setuju.

E. Maintenance ( pemeliharaan)

Pada tahapan pemeliharaan ini dimaksimalkan pengembang sistem yang telah dirancang terkait software dan hardware dapat dirancang maksimal agar sistem dapat berjalan dengan baik

\section{HASIL DAN PEMBAHASAN}

Dalam bagian hasil dan pembahasan akan dijelaskan mengenai perancangan UML dan implementasi sistem.

A. Use Case Diagram

Use Case Diagram merupakan diagram yang menampilkan proses pemodelan perangkat lunak berorientasi objek. 


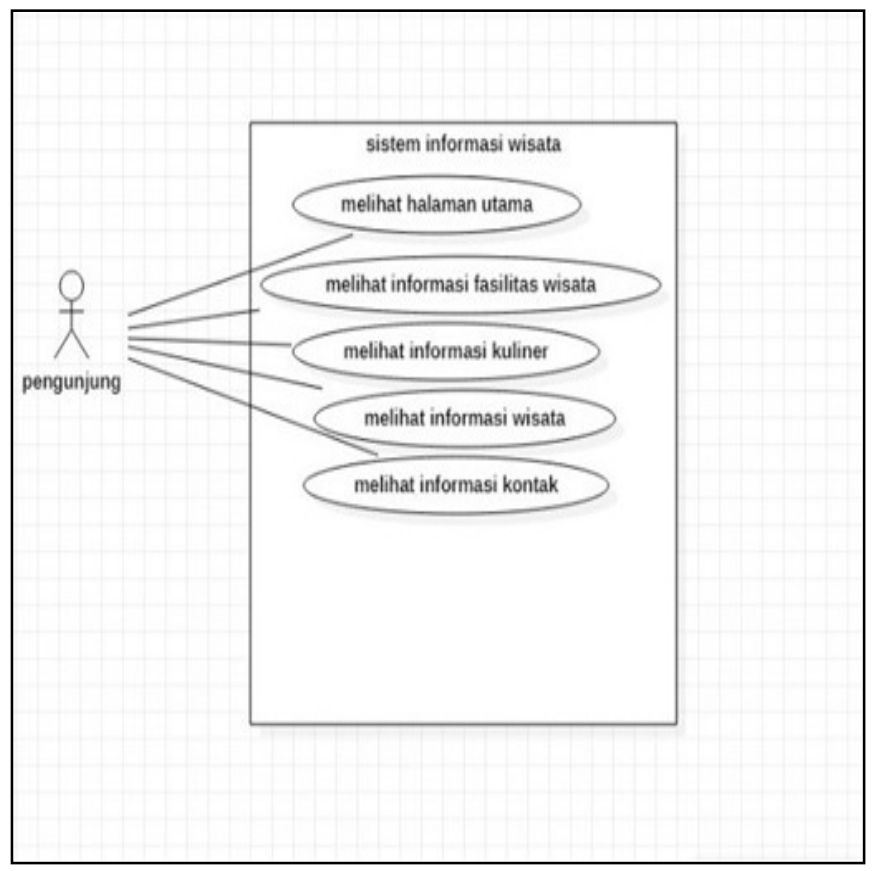

Gambar 2 Use Case Diagram

B. Class Diagram

Diagram kelas (Class Diagram) itu merupakan penggambaran dari sistem itu sendiri yang berupa program ataupun suatu menu form pilihan yang berisi tentang apa-apa saja yang saling berdekatan di gambarkan dengan Class Diagram berupa tabel kotak-kotak kecil berisi suatu kata kunci dan isi nya masing-masing yang berhubungan (Yoraeni, 2019).

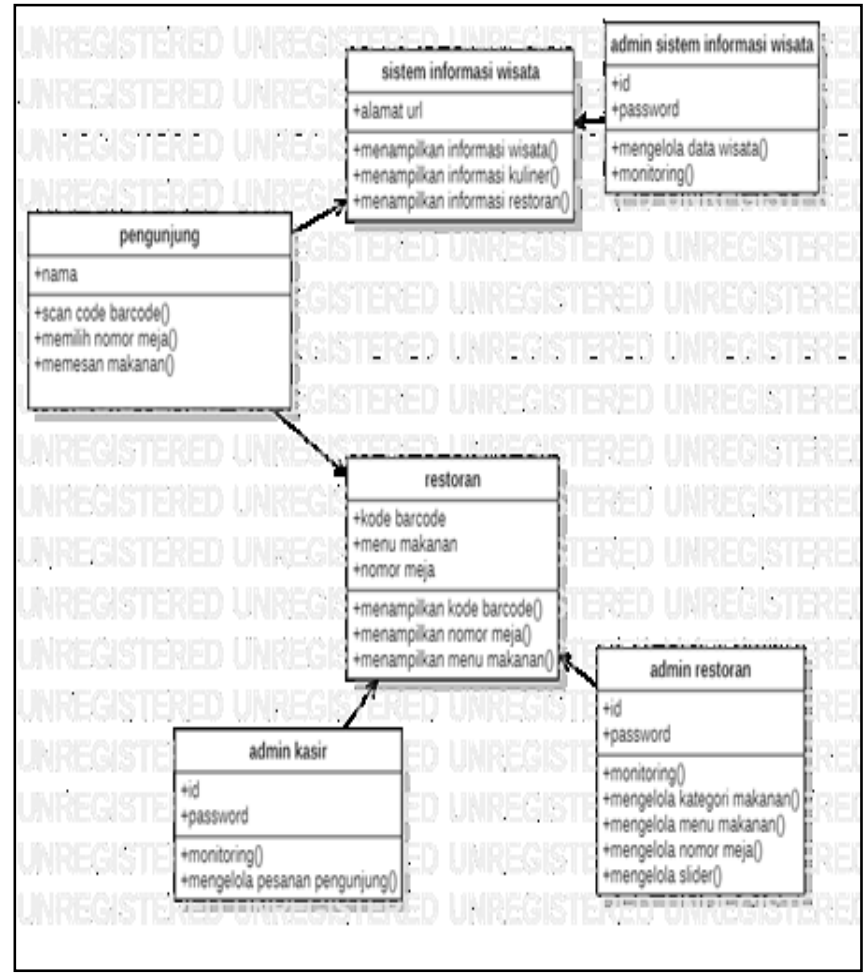

C. Implementasi

Gambar 3 Class Diagram

Dalam tahapan implementasi menjabarkan tentang bentuk atau tampilan website dan sistem informasi Wisata Waduk Pondok. 
1) Halaman Utama : Tampilan halaman utama adalah tampilan menu atau form yang akan tampil pada awal membuka sistem. Ada beberapa menu yang ada pada header halaman utama sistem ini yaitu menu Home, About, Kuliner, Informasi dan Kontak.

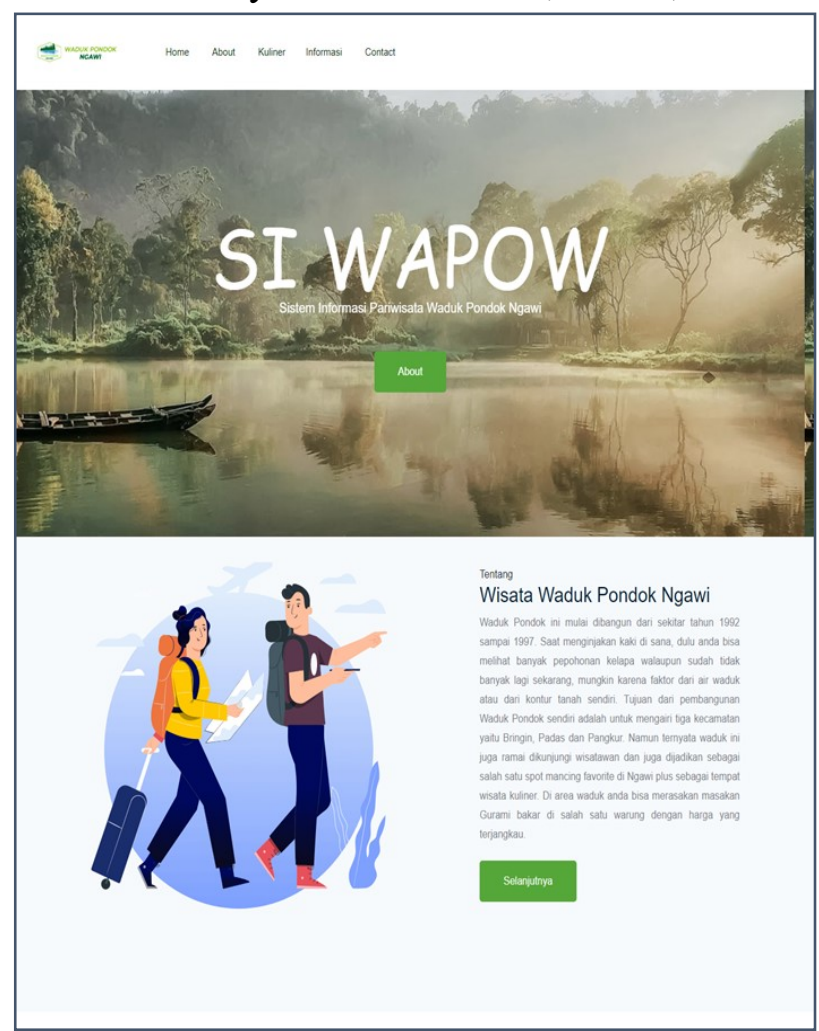

Gambar 4 Halaman Utama

2) Halaman Informasi : Halaman Informasi merupakan halaman dimana pengunjung dapat melihat gambar dan informasi detail mengenai spot - spot wisata yang ada di Waduk Pondok.

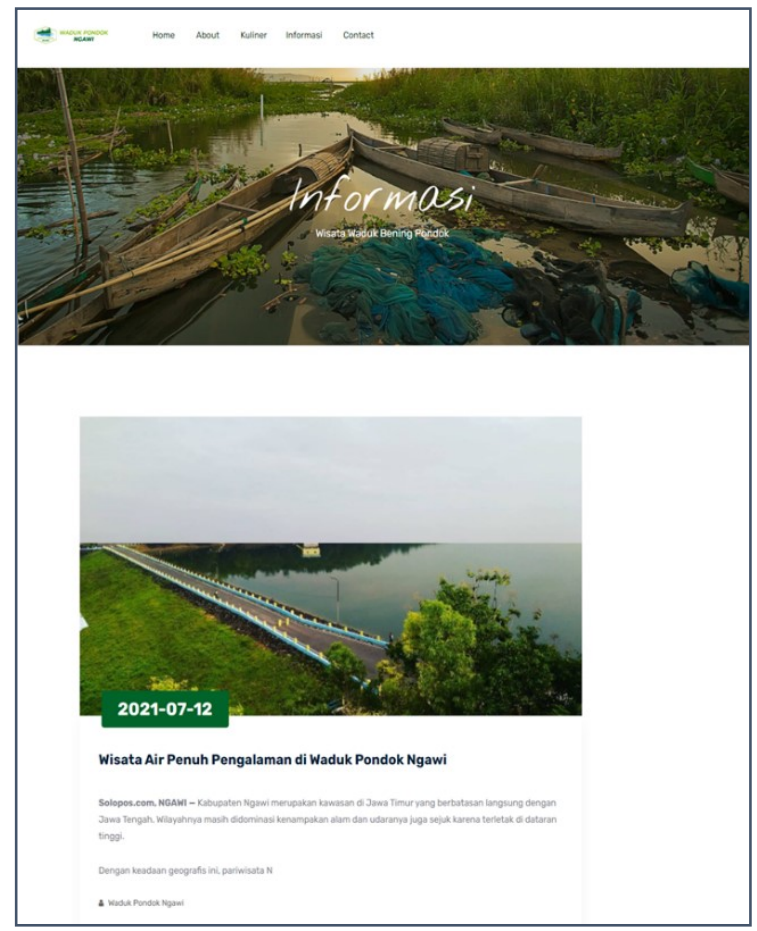

Gambar 5 Halaman Informasi 
Website : http://pilar.unmermadiun.ac.id/index.php/pilarteknologi

3) Halaman Menu Resto : Pada tampilan menu resto yang ada pada menu Kuliner menampilkan informasi detail berupa Nama menu, Kategori menu dan Harga menu.

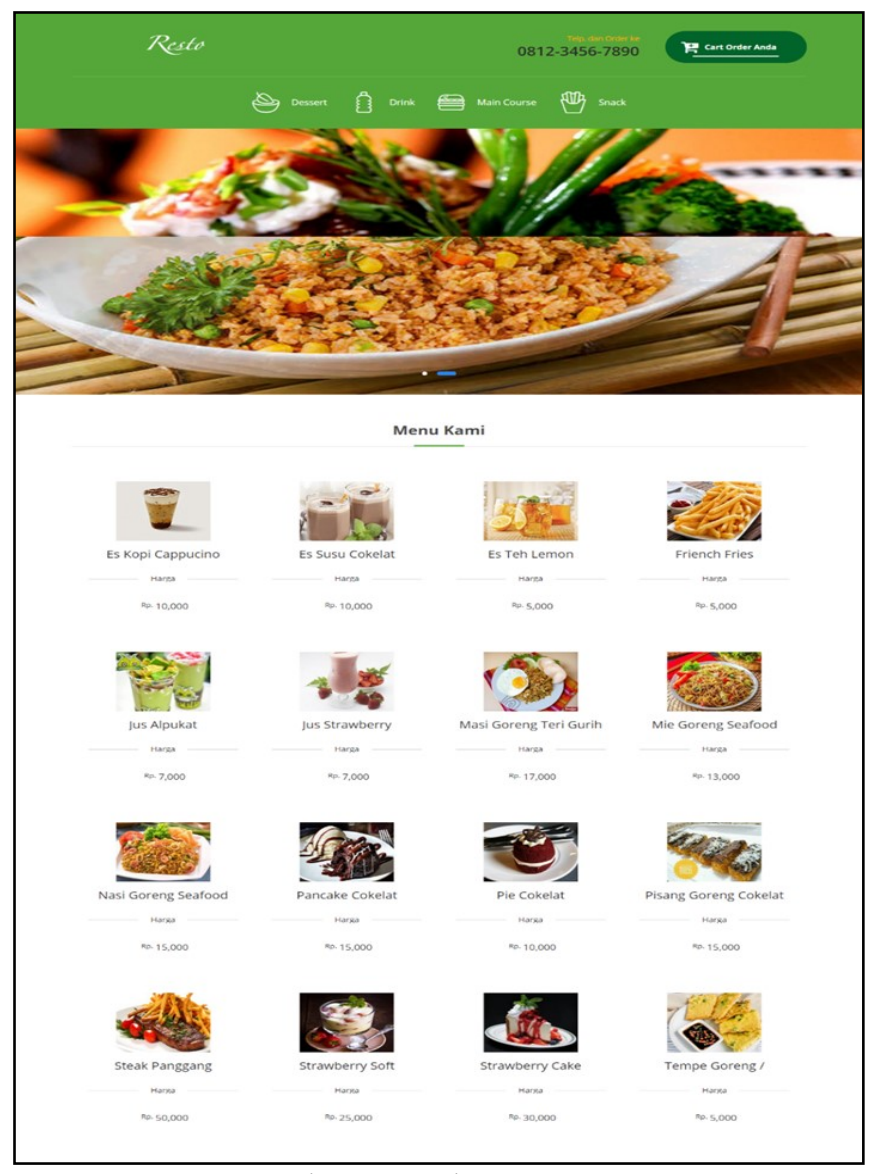

Gambar 6 Halaman Menu Resto

4) Halaman Admin : Pada menu ini menampilkan seluruh data yang diperlukan dari mulai fitur yang disediakan untuk admin. Dari jumlah Admin, objek wisata dan kuliner.

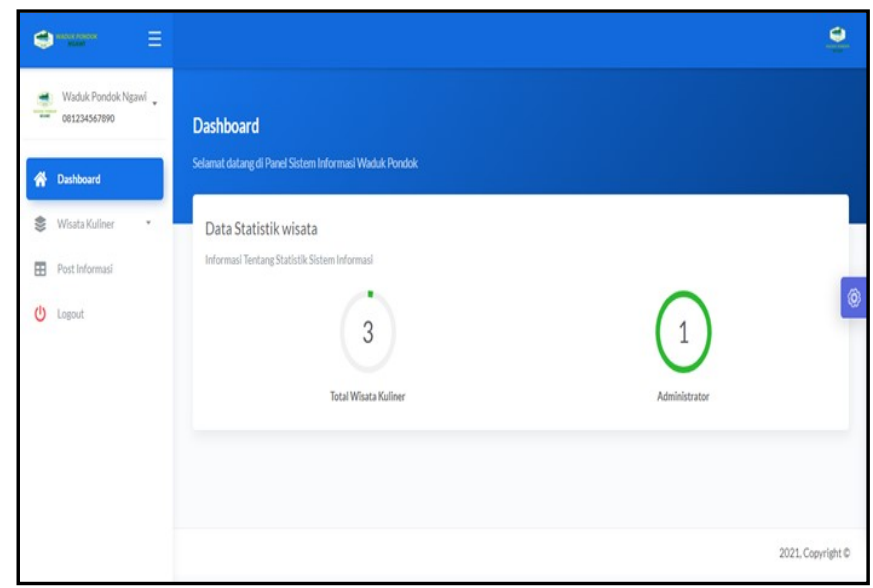

Gambar 7 Halaman Admin 
Website : http://pilar.unmermadiun.ac.id/index.php/pilarteknologi

\section{KESIMPULAN DAN SARAN}

Berdasarkan hasil pembahasan perancangan dan pembuatan Web profil dan sistem informasi terintegrasi Waduk Pondok Ngawi maka dapat diambil kesimpulan yaitu :

1. Web profil dan sistem informasi Waduk Pondok menyajikan informasi-informasi tentang Waduk Pondok, dimana informasi yang dimuat dalam website ini terintegrasi dengan informasi pendukung lainnya. Web profil dan sistem informasi Waduk Pondok memuat informasi tentang fasilitas wisata dan informasi detail mengenai resto yang ada beserta menu - menu makanan dan minuman lengkap dengan harga dari menu tersebut.

2. Web profil dan sistem informasi Waduk Pondok memberikan informasi bagi pengguna dan memudahkan bagi wisatawan dalam mencari informasi terkait Wisata Waduk Pondok dan sebagai media promosi untuk mengenalkan Wisata Waduk Pondok kepada khalayak banyak. Selain itu, dengan web profil dan sistem informasi yang terintegrasi satu dengan lainnya akan semakin memudahkan masyarakat dan wisatawan dalam mengakses informasi yang berhubungan dengan Wisata Waduk Pondok.

\section{UCAPAN TERIMA KASIH}

Ucapan terimakasih penulis ucapkan kepada Bapak Ridho Pamungkas, S. Kom., M. Kom dan Bapak Syaifulloh S. Kom., M. Kom selaku dosen pembimbing yang telah meluangkan waktunya untuk membimbing dan berbagi ilmu dan masukan yang telah diberikan.

\section{DAFTAR PUSTAKA}

Aceh, B., \& Sapnaranda, S. (2017). Fakultas tarbiyah dan keguruan universitas islam negeri ar-raniry darussalam - banda aceh 2017/1438 h. 170205043, 1-127.

Afriana, M., Ibrahim, A., \& Simarmata, T. S. (2016). PENGEMBANGAN SISTEM INFORMASI PARIWISATA KOTA PALEMBANG BERBASIS MOBILE ANDROID. Jurnal Sistem Informasi, 8(2), 1080-1094.

Amrina, E., Kamil, I., Triha, H., \& Yulianto, A. A. (2019). Sistem Informasi Pemasaran Biduk Wisata Pulau Berbasis Web Mobile (Studi Kasus di Sungai Pisang, Padang, $\begin{array}{lllll}\text { Sumatera Barat). Jurnal Optimasi Sistem Industri, } 18(2), & 142 .\end{array}$ https://doi.org/10.25077/josi.v18.n2.p142-152.2019

Hasugian, P. S. (2018). Perancangan Website Sebagai Media Promosi Dan Informasi. Journal Of Informatic Pelita Nusantara, 3(1), 82-86.

Josi, A. (2017). Penerapan Metode Prototyping Dalam Membangun Website Desa (Studi Kasus Desa Sugihan Kecamatan Rambang). Jti, 9(1), 50-57.

Kartawidjaja, J. (2020). OPTIMASI PENJADWALAN UJIAN PRA SKRIPSI DAN SKRIPSI MENGGUNAKAN METODE ALGORITMA GENETIKA (STUDI. Orphanet Journal of Rare Diseases, 21(1), 1-9.

Kartini, E. (2017). Sistem Informasi Wisata Kuliner di Kota Medan Berbasis Web. 2(2), 139145.

Kuswara, A., Supriatna, A. D., \& Gunadhi, E. (2020). Sistem Informasi Wisata Pantai Berbasis Web Di Kabupaten Garut. Jurnal Algoritma, 16(2), 201-207. https://doi.org/10.33364/algoritma/v.16-2.201 
Lubis, B. O. (2016). Sistem Informasi Penjualan Voucher Belanja Pada PT. Plaza Iindonesia Reality Tbk. Jakarta. Jurnal Informatika, III(1), 51-62.

Nurhayati, S., \& Ristanto, V. G. (2017). Sistem Informasi Pariwisata Provinsi Papua Berbasis Web. Seminar Nasional APTIKOM (SEMNASTIKOM), 3(1), 1-13.

Purnama, S., Tivianton, T. A., Cahyadi, A., Febriarta, E., \& Artikel, S. (2019). JURNAL GEOGRAFI Kajian Daerah Imbuhan Airtanah di Kabupaten Ngawi. 16(1), 54-59. https://doi.org/10.15294/jg.v16i1.18385

Rifai, A., \& Yuniar, Y. P. (2019). Penerapan Metode Waterfall Dalam Perancangan Sistem Informasi Ujian Pada SMK Indonesia Global Berbasis Web. Jurnal Khatulistiwa Informatika, 7(1), 1-6. https://doi.org/10.31294/jki.v7i1.64

Sasmito, G. W. (2017). Penerapan Metode Waterfall Pada Desain Sistem Informasi Geografis Industri Kabupaten Tegal. Jurnal Informatika:Jurnal Pengembangan IT (JPIT), 2(1), 6 12.

Setiawan, I. R. (2016). Pengembangan Sumber Daya Manusia di Bidang Pariwisata: Perspektif Potensi Wisata Daerah Berkembang. Jurnal Penelitian Manajemen Terapan, 1(1), 23-35. https://journal.stieken.ac.id/index.php/penataran/article/view/301

Susilo, H. (2019). Optimasi Pengelolaan Waduk Pondok Ngawi Jawa Timur. JURNAL PILAR TEKNOLOGI: Jurnal Ilmiah Ilmu Ilmu Teknik, 4(2), 54-58. https://doi.org/10.33319/piltek.v4i2.40

Susilo, M. (2018). Rancang Bangun Website Toko Online Menggunakan Metode Waterfall. InfoTekJar (Jurnal Nasional Informatika dan Teknologi Jaringan), 2(2), 98-105. https://doi.org/10.30743/infotekjar.v2i2.171

Syahputra, R., Utara, S., \& Pendahuluan, A. (n.d.). Strategi pemasaran dalam alquran tentang promosi penjualan. 83-88.

Yoraeni, A. (2019). Perancangan Sistem Berorientasi Objeck.

Yuhana, A. N., \& Aminy, F. A. (2019). Optimalisasi Peran Guru Pendidikan Agama Islam Sebagai Konselor dalam Mengatasi Masalah Belajar Siswa. Jurnal Penelitian Pendidikan Islam, 7(1), 79. https://doi.org/10.36667/jppi.v7i1.357 